\title{
Gaia e Ctônia
}

Gaia and Ctonia

Giorgio Agamben

Tradução do original italiano e resumo por Andityas Soares de Moura Costa Matos

Resumo: Neste breve e denso ensaio, o filósofo italiano compara duas dimensões da terra conforme pensadas originalmente pelos gregos, a superfície onde tudo floresce, personificada na deusa Gaia, e os misteriosos subterrâneos compreendidos sob o signo de Ctônia. Contudo, mais do que uma reflexão estratigráfica, com $\circ$ presente texto Agamben pretende indicar a inseparabilidade da esfera dos mortos em relação àquela dos vivos, concluindo que uma sociedade que, como a nossa, rompeu seus laços com Ctônia, na realidade cria para si uma dimensão em que a vida se torna impossível, assim como a política.

Palavras-chave: Gaia; Ctônia; terra; vida; morte.

Abstract: In this brief and dense essay, the Italian philosopher compares two dimensions of the earth as originally thought by the Greeks, the surface where everything flourishes, personified in the goddess Gaia, and the mysterious subterranean areas understood under the sign of Ctonia. However, more than a stratigraphic reflection, with this text Agamben intends to indicate the inseparability of the sphere of the dead in relation to that of the living, concluding that a society that, like ours, broke its ties with Ctonia, in reality creates for itself a dimension in which life becomes impossible, as well as politics.
Keywords: Gaia; Ctonia; Earth; life; death.

\section{I.}

No grego clássico, a terra tem dos nomes que correspondem a duas entidades distintas, talvez até opostas: ge (ou gaia) e chthon. Ao contrário de uma teoria hoje difundida, os homens não habitam apenas gaia, mas tem sobretudo a ver com chthon, que em algumas narrativas míticas assume a forma de uma deusa cujo nome é Chthonie, Ctônia. Assim, no início da teologia de Ferécides de Siro, são elencadas três divindades: Zeus, Chronos e Chtonìe, acrescentando o autor que "a Chtonìe coube $\circ$ nome de $\mathrm{Ge}$ depois que Zeus a presentou com a terra (gen)". Ainda que a identidade da deusa permaneça indefinida, em relação a ela Ge é uma figura acessória, quase um nome ulterior de Chtonìe. Não menos significativo é que em Homero os homens sejam definidos com $\circ$ adjetivo epichtonioi (ctônicos, que estão sobre chthon), enquanto o adjetivo epigaios ou epigeios se refere apenas às plantas e aos animais.

O fato é que chton e ge nomeiam dois aspectos de terra por assim dizer geologicamente antitéticos: chton é a face externa do mundo inferior, a terra da superfície para baixo, ge é a terra da superfície para cima, a face que a terra volta para o céu. A essa diversidade 
estratigráfica corresponde a diferença das práticas e das funções: chthon não é cultivável e dela não se pode extrair alimento, escapa da oposição cidade/campo e não é um bem que possa ser possuído; ge, por outro lado, como o epônimo hino homérico recorda com ênfase, "nutre tudo aquilo que está sobre chthon" (epi chthoni) e produz colheitas $e$ bens que enriquecem os homens: para aqueles que ge honra com sua benevolência, "os sulcos da gleba que dão vida estão carregados de frutos, nos campos prospera o gado e a casa se enche de riquezas e governam com leis justas as cidades das belas mulheres" (vv. 9-11).

A teogonia de Ferécides contém o mais antigo testemunho sobre a relação entre Ge e Chthon, entre Gaia e Ctônia. Um fragmento conservado de Clemente de Alexandria define a natureza dessa relação ao detalhar que Zeus se une em matrimônio com Chthonìe e quando, segundo o rito nupcial dos anakalypteria, a esposa retira o véu e aparece nua para o esposo, Zeus a recobre com "um manto grande e belo", no qual "bordou com várias cores Ge e Ogeno (Oceano)." Chthon, a terra inferior, é então algo abissal que não pode se mostrar em sua nudez e a veste com a qual $\circ$ deus a recobre não é outra coisa que Gaia, a terra superior. Uma passagem da Caverna das ninfas de Porfírio nos informa que Ferécides caracterizava a dimensão ctônica como profundidade, "falando de recessos (mychous), fossos (bothrous), cavernas (antra)", concebidos como as portas (thyras, pylas) que as almas cruzam no nascimento e na morte. A terra é uma realidade dupla: Ctônia é - fundo informe e escondido que Gaia cobre com seu variado bordado de colinas, campos floridos, aldeias, bosques e rebanhos.
Na Teogônia de Hesíodo a terra também tem duas faces. Gaia, "base sólida de todas as coisas", é a primeira criatura do Chaos, mas o elemento ctônico é evocado logo depois e, como em Ferécides, definido com o termo mychos: "o escuro Tártaro no profundo da terra de amplos caminhos (mychoi chthonos eyryodeies)". Onde a diferença estratigráfica entre os dois aspectos da terra aparece com maior clareza é no hino homérico a Deméter. Já no início, quando o poeta descreve a cena do rapto de Perséfone enquanto recolhe flores, Gaia é evocada duas vezes, em ambos os casos como a superfície florida que a terra dirige ao céu: "as rosas, os açafrões, as belas violetas em um prado macio e as íris, os jacintos e os narcisos que Gaia faz crescer segundo a vontade do deus" (...) "ao perfume das flores todo o céu no alto e a terra sorriram". Mas nesse mesmo instante, "chthon dos vastos caminhos se escancarou (chane) na planície de Nísio e daí saiu (orousen) com seus cavalos imortais o senhor dos muitos hóspedes". Que se trata de um movimento que vem debaixo em direção à superfície é sublinhado pelo verbo ornymi, que significa "subir, alçar-se", quase como que do fundo ctônico da terra o deus aflorasse sobre Gaia, a face da terra que olha em direção ao céu. Mais a frente, quando é a própria Perséfone a narrar a Deméter o seu rapto, o movimento se inverte e é Gaia, por sua vez, que se abre (gaia d'enerthe koresen) para que "o senhor dos muitos hóspedes" possa arrastá-la para debaixo da terra com seu carro de ouro (vv. 429-431). É como se a terra tivesse duas portas ou aberturas, uma que se abre do profundo em direção a Gea e uma que de Gea conduz ao abismo de Ctônia.

Na realidade, não se trata de duas portas, mas de um só limiar que pertence inteiramente a chthon. $O$ verbo que no 
hino se refere a Gaia não é chaino, escancarar, mas choreo, que significa simplesmente "abrir espaço". Gaia não se abre, mas abre espaço para o trânsito de Proserpina; a própria ideia de uma passagem entre o alto e o baixo, de uma profundidade (profundus: altus et fundus) é intimamente ctônica e, como a Sibila recorda a Eneias, a porta de Dite é sobretudo voltada para o inferior (facilis descensus Averno...). O termo latino correspondente a chthon não é tellus, que designa uma extensão horizontal, mas humus, que implica uma direção para baixo (cf. humare, enterrar), e é significativo que dele tenha sido tirado o nome para o homem (hominem appellari quia sit humo natus). Que no mundo clássico ○ homem seja "humano" - ou seja, terrestre - nada tem a ver com Gaia, com a superfície da terra que olha o céu, mas antes de tudo com uma íntima conexão com a esfera ctônia da profundidade.

Que chthon evoque a ideia de uma abertura ou de uma passagem é evidente no adjetivo que em Homero e em Hesíodo acompanha constantemente o termo: eyryodeia, que podemos traduzir como "do amplo caminho" só se não nos esquecermos que odos evoca a ideia do trânsito em direção a uma meta, nesse caso o mundo dos mortos, uma viagem que todos estamos destinados a fazer (é possível que ao escrever facilis descensos Virgílio tenha se recordado da fórmula homérica).

Em Roma uma abertura circular chamada mundus, que segundo a lenda foi escavada por Rômulo no momento de fundação da cidade, punha em comunicação o mundo dos vivos com aquele ctônico dos mortos. A abertura, fechada por uma pedra chamada manalis lapis, era aberta três vezes por ano, e naqueles dias, nos quais se dizia que mundus patet, o mundo está aberto, "as coisas ocultas e escondidas da religião dos manes eram trazidas à luz e reveladas" e quase todas as atividades públicas eram suspensas. Em um artigo exemplar, Vendryes demonstrou que 0 significa original do nosso termo "mundo" não é, como sempre se sustentou, uma tradução do grego kosmos, mas deriva precisamente do limiar circular que desvelava o "mundo" dos mortos. A cidade antiga se funda sobre o "mundo" porque os homens habitam na abertura que une a terra celeste e aquela subterrânea, o mundo dos vivos e aquele dos mortos, o presente e o passado, e é por meio da relação entre esses dois mundos que se torna possível para eles orientar suas ações e encontrar inspiração para o futuro.

O homem é não só ligado no seu próprio nome à esfera ctônica, mas também o seu mundo e o próprio horizonte de sua existência confinam com os recessos de Ctônia. O homem é, no sentido literal do termo, um ser do profundo.

\section{II.}

Uma cultura ctônica por excelência é a etrusca. Quem percorre atônito as necrópoles esparsas nos campos da Tuscia percebe imediatamente que os etruscos habitavam Ctônia e não Gaia, não só porque deles nos restou essencialmente $o$ que tinha a ver com os mortos, mas também e sobretudo porque, ainda que os locais que escolheram para suas moradas - chamá-las de cidades seria talvez impróprio - estejam aparentemente sob a superfície de Gaia, na verdade eles se sentiam em casa nas profundezas verticais de chthon. Daí seu gosto pelas cavernas e outros recessos escavados na pedra, daí sua predileção pelos altos desfiladeiros e as gargantas, as paredes íngremes de rocha vulcânica 
que se precipitam em direção a um rio ou a um riacho. Quem de repente se vê diante de Cava Buia perto de Blera ou nas ruas cravadas na rocha em San Giuliano sabe que não se encontra mais sobre a superfície de Gaia, mas certamente ad portam inferi, em uma das passagens que penetram nos declives de Ctônia.

Esse caráter inconfundivelmente subterrâneo dos lugares etruscos, se comparado a outras regiões da Itália, pode ser também expresso dizendo que aquilo que temos diante dos olhos não é propriamente uma paisagem. A afável e costumeira paisagem que se abraça serenamente com o olhar e desaparece no horizonte pertence a Gaia: na verticalidade ctônica toda paisagem some, todo horizonte desaparece e deixa lugar ao rosto feroz e nunca visto da natureza. E aqui, nos canais rebeldes e nos abismos, onde não sabemos o que fazer com a paisagem, a terra é mais tenaz e inflexível do que qualquer pietas paisagística - às portas de Dite o deus se fez tão próximo e resistente que já não exigia mais nenhuma religião.

É graças a essa inabalável dedicação ctônica que os etruscos construíram e cuidaram com tanta diligência das casas dos seus mortos, e não, como se poderia pensar, o contrário. Não amavam a morte mais do que a vida, mas a vida era para eles inseparável da profundidade de Ctônia, podiam habitar os vales de Gaia e cultivar seus campos contanto que nunca se esquecessem do seu verdadeiro lar vertical. Por isso, nas tumbas escavadas na rocha ou nos túmulos, não temos que lidar apenas com os mortos, não imaginamos só os corpos deitados sobre sarcófagos vazios, mas percebemos juntos os movimentos, os gestos e os desejos dos vivos que os construíram. Que a vida seja tanto mais amável quanto mais ternamente custodia em si a memória de Ctônia, que seja possível edificar uma civilização sem nunca excluir a esfera dos mortos, que haja entre o presente e o passado e entre os viventes e os mortos uma intensa comunidade e uma continuidade ininterrupta - este é o legado que esse povo transmitiu à humanidade.

III.

Em 1979, James E. Lovelock, um químico inglês que tinha colaborado ativamente no programa de exploração espacial da NASA, publicou Gaia: a new look at life on Earth. No centro do livro há uma hipótese que um artigo escrito com Lynn Margulis cinco anos antes na revista Tellus tinha antecipado nos seguintes termos: "o conjunto dos organismos viventes que constituem a biosfera podem agir como uma entidade singular para regular a composição química, o $\mathrm{Ph}$ superficial e talvez até mesmo o clima. Chamamos 'hipótese Gaia' a concepção da biosfera como um sistema ativo de controle e adaptação, capaz de manter a terra em homeostase". A escolha do termo Gaia, que foi sugerido a Lovelock por William Golding - um escritor que tinha descrito magistralmente a perversa vocação da humanidade no romance $\mathrm{O}$ senhor das moscas - não é certamente casual: como - artigo detalha, os autores identificavam os limites da vida na atmosfera e se interessavam "só em menor medida pelos limites internos constituídos pela interface entre as partes internas da terra, não sujeitas à influência dos processos da superfície" (p. 4). Todavia, não menos significativo é um fato que os autores não parecem - ao menos naquele momento - considerar, qual seja, que a devastação e a polvição de Gaia atingiram seu nível máximo exatamente quando os habitantes da 
terra decidiram extrair a energia necessária às suas novas e crescentes necessidades das profundezas de Ctônia, sob a forma daquele resíduo fóssil de milhões de seres viventes que viveram em um passado remoto que chamamos de petróleo.

Segundo toda evidência, a identificação dos limites da biosfera com a superfície da terra e com a atmosfera não pode ser mantida: a biosfera não pode existir sem a troca e a "interface" com a tanatosfera ctônica, os vivos e os mortos devem ser pensados juntos.

O que aconteceu na modernidade é que, de fato, os homens se esqueceram e recalcaram sua relação com a esfera ctônica; não habitam mais Chthon, mas apenas Gaia. Todavia, quanto mais eliminavam da sua vida a esfera da morte, mais a sua existência de tornava invivível; quanto mais perdiam toda familiaridade com as profundidades de Ctônia, reduzida como todo resto a objeto de exploração, mais a amável superfície de Gaia era progressivamente envenenada e destruída. E aquilo que temos hoje diante dos olhos é a extrema deriva desse recalque da morte: para salvar suas vidas de uma suposta e confusa ameaça, os homens renunciam a tudo que as torna dignas de serem vividas. E no final, Gaia, a terra já sem profundidade que perdeu toda memória do lar subterrâneo dos mortos, está agora integralmente à mercê do medo e da morte. Só poderão se curar desse medo os que reencontrarem a memória da sua dupla casa, que recordarem que humana é só aquela vida na qual Gaia e Ctônia permanecem inseparáveis e unidas. 